\title{
MONITORAMENTO DE LAGARTAS DE Anticarsia gemmatalis NA CULTURA DA SOJA POR DOIS MÉTODOS DE BATIDA DE PANO NOS MUNICÍPIOS DE ESPUMOSO E IBIRUBÁ, RS
}

\author{
Giovana Natali Simon ${ }^{1 *}$, Lucas Scholze Tramontini ${ }^{1}$, Jardel Henrique Kirchner ${ }^{2}$
}

\author{
${ }^{1}$ Graduando em Agronomia, Instituto Federal de Educação, Ciência e Tecnologia do Rio Grande do Sul (IFRS), \\ Campus Ibirubá - RS. *E-mail do autor correspondente: giovana_s@ @otmail.com.br \\ ${ }^{2}$ Docente do curso de Agronomia, área de atuação Engenharia Agrícola, Instituto Federal de Educação, Ciência \\ e Tecnologia do Rio Grande do Sul (IFRS), Campus Ibirubá - RS.
}

Recebido: 14/12/2020; Aceito: 19/04/2021

RESUMO: A soja é uma das culturas mais relevantes do Brasil, sendo o principal produto de exportação. Entre as pragas mais importantes da cultura está a lagarta-da-soja, Anticarsia gemmatalis que é responsável por altos índices de desfolha. O monitoramento periódico nas lavouras a fim de verificar a incidência de pragas é fundamental para realização do manejo integrado de pragas (MIP). O objetivo do trabalho foi verificar a incidência da lagarta da soja, em cada estádio fenológico da cultura e avaliar o método adequado de coleta para quantificar a densidade populacional. O experimento foi conduzido durante a safra 2019/2020 em duas áreas distintas nos municípios de Espumoso/RS e Ibirubá/RS, utilizando a cultivar BMX Ativa. Utilizou-se em ambas as áreas o delineamento inteiramente casualizado (DIC). Foram utilizados panos de batida horizontal e vertical a fim de realizar a coleta das lagartas. Verificou-se a incidência da lagarta da soja, em cada estádio fenológico da cultura e o método adequado de coleta a fim de quantificar a densidade populacional. Os resultados foram submetidos à análise de variância e ao teste Tukey a 5\% de probabilidade de erro. O início do surto de A. gemmatalis se deu em R2 em ambos os locais, e o pico populacional em Espumoso foi em R5.5 e em Ibirubá em R5. Houve necessidade de controle de acordo com a literatura somente para Ibirubá. Ambos os métodos de amostragem podem ser utilizados para monitoramento desta espécie na cultura da soja, porém, quando usados de forma mútua apresentam resultados mais concisos.

Palavras-chave Lagarta-da-soja. Monitoramento de praga. Acompanhamento populacional. Glycine max.

\section{MONITORING OF Anticarsia gemmatalis CATERPILLARS IN SOYBEAN CROP BY TWO METHODS OF CLOTH BEAT IN THE MUNICIPALITIES OF FOAMY AND IBIRUBÁ, RS}

\begin{abstract}
The soybean is one the most important crop in Brazil, being the principal commodity of exportation. Amid the most important pests of the crop is A. gemmatalis, responsible for the high rate of defoliation. Periodic monitoring in crops in order to verify the incidence of pests is essential for integratedpest management (IPM). The objective of this study was to verify the incidence of soybean caterpillar in each phenological stage of the crop
\end{abstract}


and to the appropriate collection method to quantify population density. The experiment was conducted during the harvest 2019/2020 in two distinguished between area in the municipalities of Espumoso/RS and Ibirubá/RS, using the BMX Ativa cultivar. It was used at both areas the completely randomized design (CRD). Were used horizotal beat sheet and vertical so that to quantify the population desity. The results were subjected to analysis of variance and the tukey test at 5\% probability of error. The beginning of outbreak of A.gemmatalis it happened in R2 at boths areas, and the population peak at Espumoso were at R5.5, and at Ibirubá R5. There were a need to control according to the literature only for Ibirubá. Both collection methods can be used to monitor this species in the soybean crop, when used together they present more concise results.

Key words: Soybean caterpillar. Anticarisa gemmatalis. Pest monitoring. Population monitoring. Glycine max

\section{INTRODUÇÃO}

A soja (Glycine max) pertence à família Fabaceae, tendo como centro de origem o continente asiático (GAZZONI, 2018). Esta cultura desempenha papel importante na economia brasileira, sendo a principal commodity exportada.

Dentre os fatores que limitam a produção de soja estão os problemas fitossanitários que podem ser decorrentes da presença de insetos-praga, como lagartas e percevejos (CAMPOS et $a l .$, 2018).

A utilização do Manejo Integrado de Pragas (MIP) na cultura da soja é uma alternativa que se mostra eficiente, pois consiste na aplicação de vários métodos de controle, a fim de evitar danos a produtividade da espécie, controlando as principais pragas, baseando-se na amostragem das populações das pragas e de seus inimigos naturais para monitorar os níveis populacionais, empreendendo as medidas de controle curativas quando os níveis de controle forem alcançados, assim, diminuindo o custo com produtos fitossanitários (STABACK et al., 2020).

O monitoramento e o reconhecimento de insetos-praga podem ser efetuados através de métodos de amostragem que permitem estimar a densidade populacional aliado ao conhecimento do impacto potencial da espécie, servindo de suporte a necessidade de manejo para determinada praga (STURMER et al., 2014). Dentre estes métodos, os mais utilizados na cultura da soja são o pano de batida horizontal e o pano de batida vertical, sendo que ambos já foram demonstrados ser eficientes para a amostragem de lagarta da soja (STÜRMER et al., 2012).

Dentre as pragas que causam danos na cultura da soja, destaca-se a Anticarsia gemmatalis, popularmente denominada Lagarta da Soja. Ela pode ser apontada como a principal desfolhadora, com danos que variam desde a desfolha parcial até a destruição completa da planta (SAVIO et al., 2008), sendo que a intensidade dos danos se acentua ao decorrer do seu crescimento. 
Além disso, a utilização do método de coleta a ser utilizado é dependente da cultura, desenvolvimento fenológico, tipo de praga a qual deseja monitor, facilidade de utilização, velocidade de uso, custo envolvido e deve ser confortável ao avaliador (WADE et al., 2006).

O objetivo do trabalho foi verificar a incidência da lagarta da soja, em cada estádio fenológico da cultura da soja e avaliar o método adequado de coleta a fim de quantificar a densidade populacional.

\section{MATERIAL E MÉTODOS}

\section{Localização e Caracterização do Experimento}

O experimento foi conduzido durante a safra 2019/2020 em duas áreas distintas, a primeira em uma propriedade particular no município de Espumoso-RS, com as coordenadas geográficas latitude $28^{\circ} 42^{\prime} 24.5^{\prime \prime} \mathrm{S}$ e longitude $52^{\circ} 48^{\prime} 03.65^{\prime}$ O', situado $381 \mathrm{~m}$ acima do nível do mar e a outra na área didática do Instituto Federal de Educação, Ciência e Tecnologia do Rio Grande do Sul-Campus Ibirubá, situado no município de Ibirubá-RS sob as coordenadas geográficas latitude $28^{\circ} 37^{\prime} 39^{\prime \prime S}$ e longitude 5305'23”O, situado $441 \mathrm{~m}$ acima do nível do mar.

O clima de ambos os municípios, de acordo com Álvares et al. (2013), é subtropical úmido, apresentando chuvas bem distribuídas ao longo de todo o ano e verões quentes. O solo O solo é caracterizado como Latossolo Vermelho distroférrico típico (SANTOS, 2018).

A cultivar de soja utilizada na semeadura para ambos os experimentos foi a BMX Ativa, devido a sua boa adaptabilidade na região, possui grupo de maturação 5.6, com hábito de crescimento determinado, ciclo médio de 125 dias. As sementes receberam tratamento com inseticida e fungicida anteriormente a semeadura. A semeadura no município de Espumoso foi realizada em 23/10/19, com densidade de semeadura de 17 sementes/m linear e espaçamento de 0,42 e, em Ibirubá, no dia 25/10/19, com 14 sementes/m linear com espaçamento de 0,45 .

Os tratos culturais seguiram a recomendação técnica para cultura, sendo utilizado 300 $\mathrm{kg} /$ ha de adubação química na fórmula N2-P23-K23 em Espumoso e N5-P20-K20 em Ibirubá. Os manejos fitossanitários com herbicidas e fungicidas foram uniformes sempre que houve necessidade. Durante todo o desenvolvimento da cultura não se utilizou inseticidas.

O delineamento experimental utilizado em ambas as áreas foi DIC (delineamento inteiramente casualizado) devido às condições homogêneas da área. Em Espumoso, utilizouse parcelas de $30 \mathrm{~m} \times 6,72 \mathrm{~m}$, totalizando 201,6 $\mathrm{m}^{2}$, compreendendo 8 linhas de cultivoe o espaçamento entre linhas de semeadura de $0,42 \mathrm{~cm}$. Em Ibirubá, as parcelas foram de 12,5 m x 50, totalizando $625 \mathrm{~m}^{2}$, utilizando o espaçamento entre linha de $0,45 \mathrm{~cm}$, compreendendo 28 linhas de cultivo.

A quantificação da população da lagarta da soja foi feita usando, como método de coleta, os panos de batida horizontal e vertical, devido a fácil aplicabilidade no campo. As lagartas eram coletadas, analisadas, identificadas e quantificadas visualmente e, em seguida, devolvidas à lavoura, afim de que continuassem seu ciclo biológico na lavoura. 
Para a determinação dos estádios fenológicos da soja, utilizou-se a metodologia de descrição proposta por Fehr e Caviness (1977), devido a sua ampla utilização no mundo. Essa metodologia sofreu algumas modificações, sendo adaptadas por Hanway e Thompson (1977), onde os autores dão maior detalhamento para a descrição do estádio R5. Essa metodologia divide o ciclo da cultura da soja, em dois estágios, sendo vegetativo, o qual é designado pela letra V e o estágio reprodutivo representado pela letra R. Ambos os estágios são seguidos de índices numéricos que ajudam a especificar as duas etapas de desenvolvimento da cultura.

Realizaram-se cinco repetições dentro de cada parcela, com ambos os modelos de panos. As avaliações foram realizadas semanalmente a partir do a partir da emergência da cultura Através da análise dos dados obtidos, tornou-se possível a elaboração de gráficos explicativos, abordando o número total de lagartas coletadas em determinado estádio fenológico.

\section{Avaliações pelos Métodos de Pano de Batida}

Os panos de batida foram confeccionados e utilizados conforme metodologia proposta por Stürmer et al. (2014), sendo compostos por um pano branco com dimensões de $1 \mathrm{~m}$ x $1 \mathrm{~m}$ e com as extremidades fixadas em cabos de madeira.

O pano de batida horizontal era constituído de dois bastões de madeira ligados entre si por um tecido branco, com comprimento de $1 \mathrm{~m}$ e largura de $1 \mathrm{~m}$, podendo ser ajustável ao espaçamento entre linhas. Para a coleta dos insetos-praga, o pano era desenrolado no solo, entre as fileiras de soja. Em seguida, as plantas das duas fileiras movimentadas com intuito de derrubar os insetos-praga sobre o pano.

De mesmo modo, o pano de batida vertical segue a mesma metodologia, porém, na extremidade inferior, existe a presença de tubo de plástico cortado ao meio longitudinalmente, servindo como uma espécie de calha coletora dos insetos-praga. Para a coleta dos insetos, o pano é colocado verticalmente na entrelinha da cultura, e as plantas de apenas uma fileira são sacudidas contra a superfície do pano (STÜRMER et al., 2014).

As avaliações iniciaram-se após a emergência da cultura, ainda em estádio VC em ambas as áreas, sendo realizadas na parte da manhã visando descaracterizar qualquer efeito comportamental da espécie que pudesse causar efeito nos resultados. Na realização das amostragens o local escolhido para alocar os panos de batidas era aleatório, posteriormente movimentava-se as plantas, as lagartas de A. gemmatalis que caiam sobre os panos, foram contabilizadas e posteriormente devolvidas à área.

\section{Análise Estatística}

Os dados foram submetidos análise de variância (ANOVA) e quando significativos, realizou-se o teste de comparação de médias (Tukey), com nível de significância de 5\% de probabilidade de erro. Para isso, utilizou-se o programa estatístico Sisvar. 


\section{RESULTADOS E DISCUSSÃO}

De acordo com a Figura 1, pode-se evidenciar o início da presença da lagarta da soja no município de Espumoso/RS quando a cultura se encontrava em estádio reprodutivo, precisamente em $\mathrm{R} 2$, estádio em que alguns autores detectaram como pico populacional desta lagarta (SANTOS, 2018).

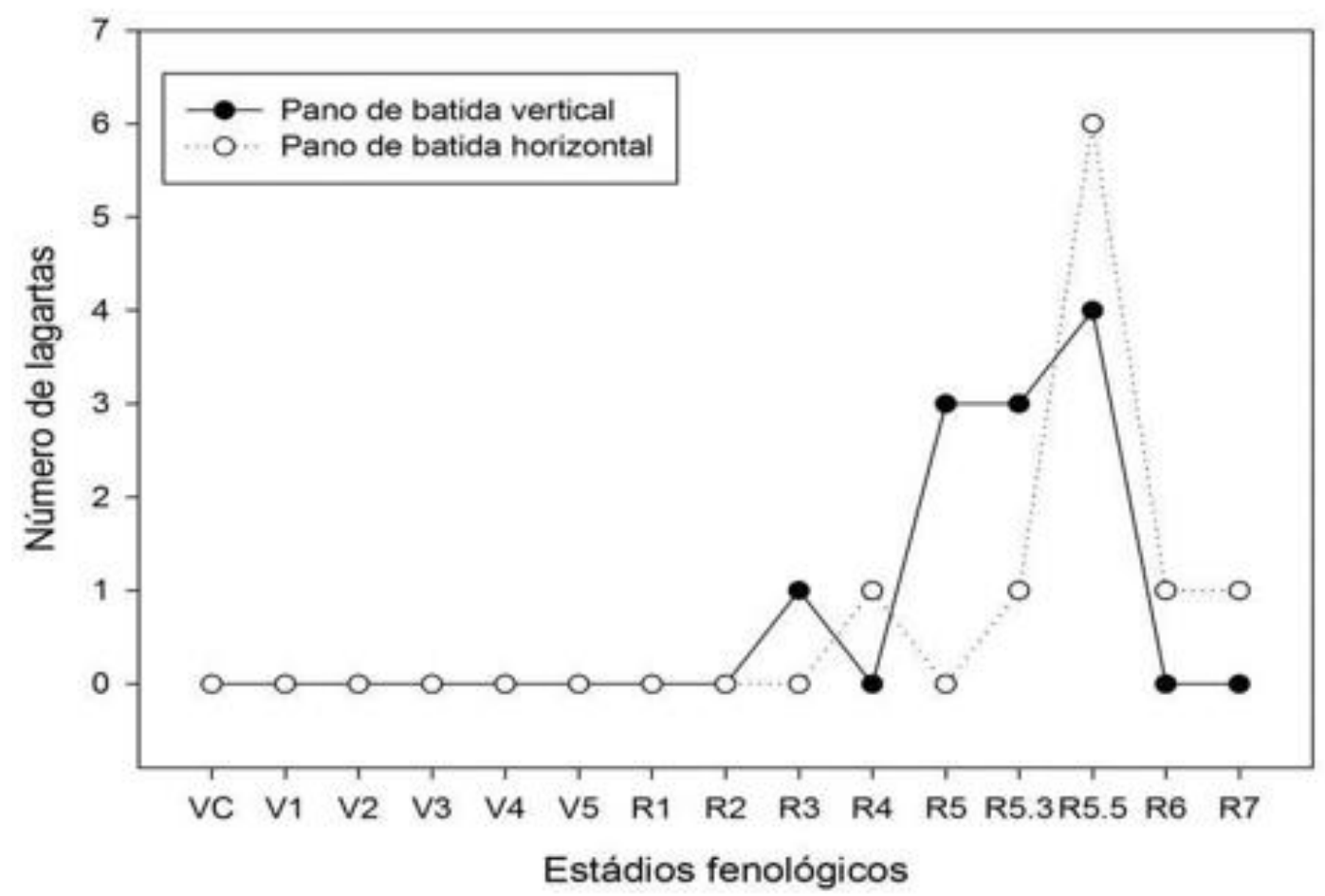

Figura 1. Número de Anticarsia gemmatalis coletadas por diferentes métodos de coleta ao longo do ciclo da soja em Espumoso/RS. Number of Anticarsia gemmatalis collected by different collection methods along the soybean cycle in Espumoso/RS.

Fonte: Autoria própria. Own authorship.

Contudo, o pico populacional se deu em R5.5, período em que a planta se encontra em fase de enchimento de grãos. Em R6 houve decréscimo no número de lagartas coletadas, permanecendo constante até o final do ciclo da planta.

No município de Ibirubá/RS, conforme Figura 2, os dados seguiram tendência semelhante aos obtidos na cidade de Espumoso/RS, tendo seu período de maior incidência em estádio reprodutivo. Foram encontradas inicialmente em estádio R3 (início da formação da vagem).

Estes dados corroboram os de Conte et al. (2018), Fehr et al. (1980), Silva (1993) e Sturmer et al. (2014), onde demonstram que a maior densidade populacional ocorreu em estádios reprodutivos, e conforme o estádio reprodutivo avança, tende a diminuir sua densidade. Como o trabalho foi conduzido na região sul do Brasil vale destacar a afirmação feita por Gazzoni et al. (1988), que citou que em latitudes mais altas, como na região sul do Brasil, os ataques ocorrem mais tardiamente. 


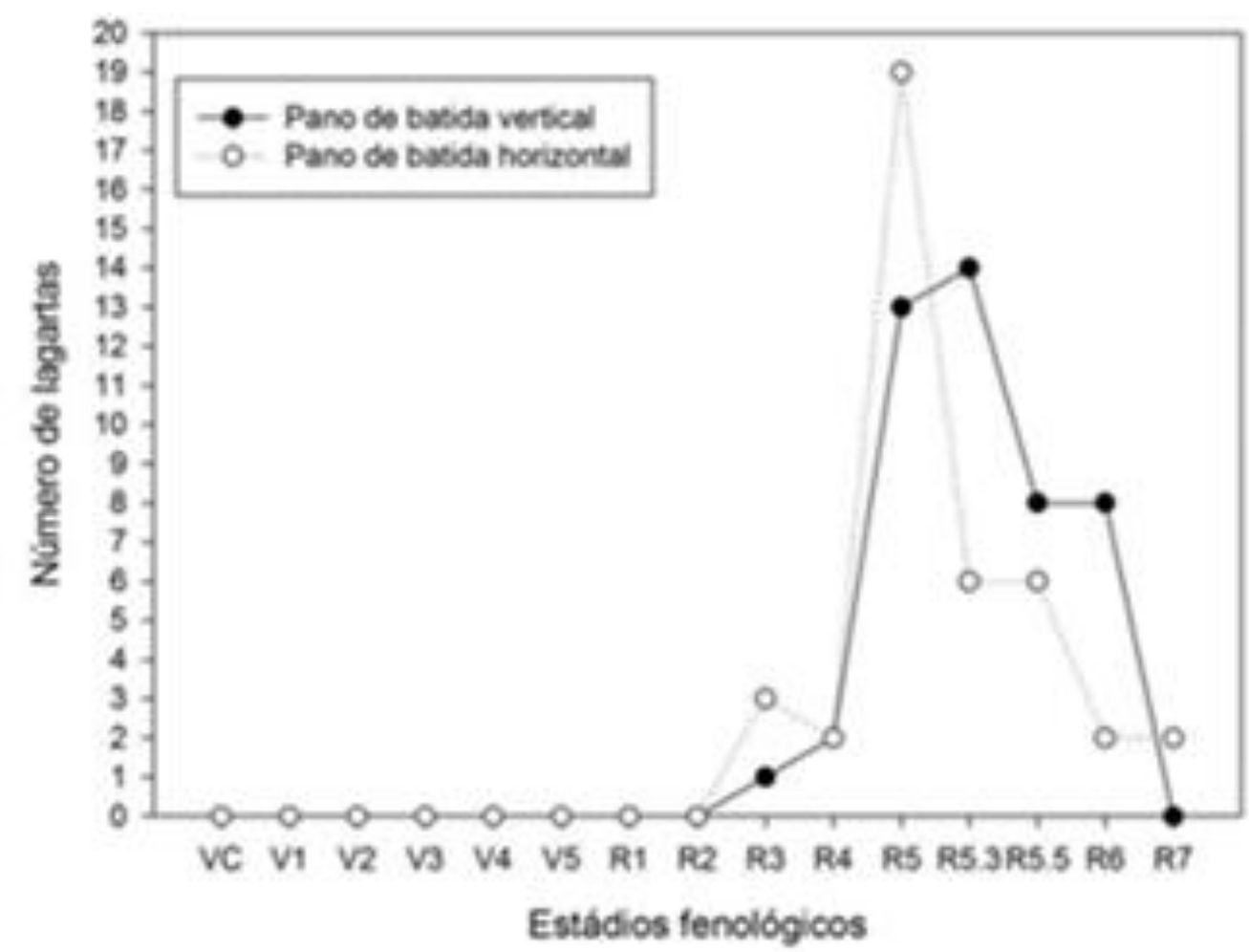

Figura 2. Número de Anticarsia gemmatalis coletadas por diferentes métodos de coleta ao longo do ciclo da soja em Ibirubá/RS. Number of Anticarsia gemmatalis collected by different collection methods along the soybean cycle in Ibirubá/RS.

Fonte: Autoria própria. Own authorship.

O número de lagartas encontradas no estádio de pico populacional no município de Ibirubá foi 3,4 vezes maior, sendo coletadas 20 lagartas (em R5) através de pano horizontal, enquanto em Espumoso, foram coletadas apenas 6 lagartas (em R5.5).

Outro fator que pode contribuir para o aparecimento de A. gemmatalis somente em estádio reprodutivo é o uso de tratamento de sementes, pois de acordo Vieira (2017), o uso de inseticidas em tratamento de sementes, retarda e reduz o consumo de área foliar de soja por essa lagarta. Essa característica é pertinente em vários princípios ativos, conforme observado no estudo.

Tabela 1. Eficiência dos métodos de amostragem utilizados para coleta da espécie. Efficiency of the sampling methods used to collect the species.

\begin{tabular}{ll}
\hline Cidade & Média de A. gemmatalis coletada \\
\hline Espumoso & $0,14 \mathrm{~b}$ \\
\hline Ibirubá & $0,50 \mathrm{a}$ \\
\hline Erro padrão & 0,067
\end{tabular}

Nota: Médias seguidas pelas mesmas letras não diferem entre si pelo teste de Tukey a 5\% de probabilidade de erro. Average followed by the same letters do not differ by Tukey's test at 5\% probability of error.

Fonte: Autoria própria. Own authorship.

Quanto ao método de coleta, o pano de batida horizontal foi o primeiro método a coletar A. gemmatalis no município de Ibirubá (Tabela 1), fato contrário na comparação com o experimento de Espumoso. Tal resultado caracteriza que para o acompanhamento visando à obtenção do início de um surto de A. gemmatalis na lavoura, ambos os panos de batida podem 
ser utilizados. Conforme Corrêa-Ferreira (2012), há possibilidade de adoção de mais de um método de amostragem devido as característica da cultura e cultivar, característica da espécie, momento que a cultura se encontra, entre outros fatores.

Em relação à eficiência dos panos, ambos os tipos (vertical e horizontal) não diferiram estatisticamente entre si (Tabela 2), demonstrando que se seguir os métodos encontrado na literatura, ambos são eficientes. Strumer (2014) em seu estudo, considerou a área como fator determinante na hora de determinar a eficiência do método de amostragem, visto que o pano horizontal abrange duas fileiras da soja e o vertical somente uma. Em sua análise utilizando este fator, determinou que o vertical leva vantagem sobre o horizontal.

Tabela 2. Número médio de lagartas coletadas em cada método de amostragem em relação ao estádio fenológico da soja cv. BMX Ativa. Average number of caterpillars collected in each sampling method in relationb to the phonological stage of soybean cv. BMX Ativa.

\begin{tabular}{|c|c|c|}
\hline \multirow[t]{3}{*}{ Estádio fenológico } & \multicolumn{2}{|c|}{ Método de coleta } \\
\hline & Pano de Batida & Pano de Batida \\
\hline & Vertical & Horizontal \\
\hline $\mathrm{VC}$ & $0 \mathrm{cA}$ & $0 \mathrm{dA}$ \\
\hline V1 & $0 \mathrm{cA}$ & $0 \mathrm{dA}$ \\
\hline V2 & $0 \mathrm{cA}$ & $0 \mathrm{dA}$ \\
\hline V3 & $0 \mathrm{cA}$ & $0 \mathrm{dA}$ \\
\hline V4 & $0 \mathrm{cA}$ & $0 \mathrm{dA}$ \\
\hline V5 & $0 \mathrm{cA}$ & $0 \mathrm{dA}$ \\
\hline R1 & $0 \mathrm{cA}$ & $0 \mathrm{dA}$ \\
\hline $\mathbf{R 2}$ & $0,3 \mathrm{cA}$ & $0 \mathrm{dA}$ \\
\hline R3 & $0,3 \mathrm{cA}$ & $0 \mathrm{dA}$ \\
\hline R4 & $0,1 \mathrm{cA}$ & $0,5 \mathrm{cdA}$ \\
\hline R5 & $0,2 \mathrm{cB}$ & $1,2 \mathrm{bcA}$ \\
\hline $\mathbf{R 5 . 3}$ & $2,1 \mathrm{aA}$ & $1,7 \mathrm{aA}$ \\
\hline R5.5 & $1,2 \mathrm{bA}$ & $1,2 \mathrm{bcA}$ \\
\hline R6 & $0,2 \mathrm{cA}$ & $0,2 \mathrm{dA}$ \\
\hline R7 & $0,3 \mathrm{cA}$ & $0 \mathrm{dA}$ \\
\hline
\end{tabular}

Nota: Médias seguidas pelas mesmas letras minúsculas na linha e maiúsculas na coluna não diferem entre si pelo teste de Tukey a 5\% de probabilidade de erro. Averages followed by the same lowercase letters on the line and uppercase in the column do not differ by Tukey's test at 5\% probability error.

Fonte: Autoria própria. Own authorship.

Ao comparar a eficiência do método dentro de cada estádio fenológico (resultados expostos na coluna), tanto pano de batida vertical, bem como pano horizontal, se mostraram mais satisfatórios quando aplicados em estádio R5.3. Na linha, em estádio R5 o uso do pano de batida horizontal se mostrou superior quando comparado ao pano vertical.

$\mathrm{Na}$ literatura existente, recomenda-se o controle químico quando a população atingir 20 lagartas por pano de batida (SOSA-GÓMEZ et al., 2010). Atualmente, o nível de dano para a tomada de decisão de controle para lagartas desfolhadoras se dá com $30 \%$ de desfolha no 
estádio vegetativo e $15 \%$ de desfolha no estádio reprodutivo, danos abaixo desses níveis, não tendem a causar redução significativa na produtividade da cultura (EMPRESA BRASILEIRA DE PESQUISA AGROPECUÁRIA - EMBRAPA 2020).

Alves et al. (2020) destacaram que níveis de desfolha em até 33,3\% tanto em estádios vegetativos quanto reprodutivos, não afetam a produtividade da soja, podendo evidenciar que os níveis estabelecidos no manejo integrado de pragas no passado continuam pertinentes nas cultivares utilizadas atualmente. Cabe destacar que neste experimento, não se analisou o nível de desfolha causado pelas lagartas desfolhadoras.

Com isso, constata-se que em nenhum momento houve necessidade de controle para esta espécie no município de Espumoso, condizente com Riffel et al. (2012) em seu estudo realizado em Júlio de Castilhos/ RS.

Em contrapartida, frequentemente os produtores da região conciliam as aplicações de inseticida juntamente com fungicida ao fechamento das entrelinhas da cultura, acarretando em custos desnecessários. Aliado a isso, o uso desses produtos sem necessidade pode ocasionar problemas ambientais e a saúde humana, além de prejudicar a população de insetos benéficos na área (TONIN et al., 2014).

No momento da semeadura, ocorreram precipitações com níveis hídricos elevados, ao decorrer do desenvolvimento da cultura, essas precipitações se deram em baixa frequência, ocasionando estresse hídrico na planta, aliado a isso, as temperaturas oscilaram frequentemente, ao longo do ciclo da cultura a temperatura média foi $22,5^{\circ} \mathrm{C}$ (INSTITUTO NACIONAL DE METEOROLOGIA - INMET, 2020), esse fator pode estar relacionado à baixa incidência de lagartas da soja, uma vez que segundo Moscardi et al. (1979) temperaturas oscilantes entre 23,9 a $29,4{ }^{\circ} \mathrm{C}$ não se mostraram favoráveis para a fecundidade desta espécie e sua longevidade tende a se comprometer.

Para o município de Ibirubá, pode ser evidenciada a necessidade de controle químico da espécie, a partir de R5, pois nesse momento foram encontradas 19 lagartas por amostragem realizada, o qual atingiu um número próximo ao recomendado na literatura, cerca de 20 lagartas por pano de batida (SOSA-GÓMEZ et al., 2010).

Quanto ao uso dos panos de batida, pode-se dizer que ambos podem ser utilizados na cultura da soja, podendo apresentar diferença quanto ao número de lagartas coletadas, devido a condições como espaçamento, população final de plantas, entre outros. Concordante de Stürmer et al. (2012); Guedes et al. (2006) que abordaram que pano vertical é eficiente para a coleta de lagartas em sistemas de amostragem.

Assim, a necessidade de monitoramento periódico nas lavouras pode ser evidenciada, uma vez que, mesmo em municípios próximos pode haver variabilidade quanto ao número de lagartas coletadas, bem como quanto ao método de amostragem mais indicado para determinado estádio fenológico. 


\section{CONCLUSÃO}

A presença de A. gemmatalis ocorreu em ambos os municípios quando a cultura se encontrava em estádios reprodutivos.

O uso de pano de batida vertical e horizontal se mostra importante no monitoramento da espécie, principalmente no que tange a decisão para efetuar controle.

Ambos os métodos de coletas podem ser utilizados em todos os estádios para monitoramento de A. gemmatalis. Contudo, recomenda-se a utilização mútua dos dois panos, pois em alguns momentos um ou outro pode se mostrar mais relevante.

Recomenda-se o constante monitoramento de A. gemmatalis, pois em municípios tão próximos houve variabilidade no número de indivíduos coletados.

\section{AGRADECIMENTOS}

O presente trabalho foi realizado com apoio do Instituto Federal de Educação, Ciência e Tecnologia do Rio Grande do Sul (IFRS).

Ao Conselho Nacional de Desenvolvimento Científico e Tecnológico (CNPq) pela concessão de bolsa de pesquisa.

\section{REFERÊNCIAS BIBLIOGRÁFICAS}

ÁlVARES, C. A.; STAPE, J. L.; SENTELHAS, P. C.; MORAES, G. J. L.; SPAROVEK, G. Köppen's climate classification map for Brazil. Meteorologische Zeitschrift, Piracicaba, v. 22, n. 6 p.711-728, 2013. https://www.schweizerbart.de/papers/metz/detail/22/82078/Koppen_s_climate_classification_ map_for_Brazil. Acesso em: 14 dez. 2020.

ALVES, G. H. T.; BALLETTINI, S. Diferentes níveis de desfolha artificial nos componentes de produção da soja. Brazilian Journal of Development, Santa Mariana. v. 6, n. 9, p.6479964815 , 2020.

Disponível

em: https://www.brazilianjournals.com/index.php/BRJD/article/view/16113 Acesso em: 14 dez. 2020.

CAMPOS, G. M. J.; ALCANTARA, E.; REZENDE, R. M. Levantamento de insetos-praga na cultura da soja. Revista da Universidade Vale do Rio Verde, Três Corações, v. 16. n. 3, p.17, 2018.2 Disponível em: http://periodicos.unincor.br/index.php/revistaunincor/article/view/5602. Acesso em: 14 dez. 2020.

CONTE, O.; OLIVEIRA, F. T.; HARGER, N.; CORRÊA-FERREIRA, B. S.; ROGGIA, S.; PRANDO, A. M.; POSSAMAI, E. J.; REIS, E. A.; MARX, E. F. Resultados do manejo integrado de pragas da soja na safra 2018/19 no Paraná. Londrina: Embrapa Soja, 2019. 65 p. (Documentos, 416.) Disponível em: https://ainfo.cnptia.embrapa.br/digital/bitstream/item/201452/1/Doc-416-OL-2.pdf. Acesso em: 14 dez. 2020. 
CORRÊA-FERREIRA, B. S. Amostragem de pragas da soja. In: HOFFMANN-CAMPO, C. B.; CORREAA-FERREIRA, B. S.; MOSCARDI, F. Soja: manejo integrado de insetos e outros artrópodes-praga. Brasília, DF: EMBRAPA, 2012. Cap. 8, p. 631-672.

EMPRESA BRASILEIRA DE PESQUISA AGROPECUÁRIA - EMBRAPA. Tecnologias de produção de soja. Londrina: Embrapa Soja, 2020. 347p. (Sistemas de produção, 17).

FEHR, W. R.; CAVINESS, C. E. Stages of soybean development. Ames: lowa State University of Science and Technology, 1977. 11 p. (Special Report, 80).

GAZZONI, D. L. A soja no Brasil é movida por inovações tecnológicas. Ciência e Cultura, São Paulo, v. 70, n. 3, p.16-18, 2018. Disponível em: http://cienciaecultura.bvs.br/scielo.php?script=sci_arttext\&pid=S000967252018000300005\&1 ng=en\&nrm=iso. Acesso em: 14 dez. 2020.

GAZZONI, D.; OLIVEIRA, E. B.; CORSO, I. C.; FERREIRA, B. S. C.; VILLAS BÔAS, G. L.; MOSCARDI, F.; PANIZZI, A. R. Manejo de Pragas da Soja. Londrina: EMBRAPA Soja, 1988. 48 p. (Circular técnica, 5). Disponível em: https://www.infoteca.cnptia.embrapa.br/bitstream/doc/951293/1/CNPSOCIR.TEC.0588.pdf. Acesso em: 14 dez. 2020.

GUEDES, J. V. C.; FARIAS, J. R.; GUARESCHI, A.; ROGGIA, S.; LORENTZ, L. H. Capacidade de coleta de dois métodos de amostragem de insetos-praga da soja em diferentes espaçamentos entre linhas. Ciência Rural, Santa Maria, v. 36, n. 4, p.1299-1302, 2006. Disponível em: https://www.scielo.br/scielo.php?pid=S010384782006000400040\&script=sci_abstract\&tlng=pt. Acesso em: 14 dez. 2020.

HANWAY, J. J.; THOMPSON, H. E. How a soybean plant develops. Ames: lowa State University of Science and Technology, 1977. 20 p. (Special Report, 53). Disponível em: https://lib.dr.iastate.edu/cgi/viewcontent.cgi?article=1050\&context=specialreports. Acesso em: 14 dez. 2020.

MOSCARDI, F. Effect of soybean crop phenology on development, leaf consumption, and oviposition of Anticarsia gemmatalis Hübner. Flórida, University Gainesville, 1979. 139 p. Disponível em: https://ufdc.ufl.edu/AA00029789/00001. Acesso em: 14 dez. 2020.

SANTOS, H. G.; JACOMINE, P. K. T.; ANJOS, L. H. C.; OLIVEIRA, V. A.; LUMBRERAS, J. F.; COELHO, M. R.; ALMEIDA, J. A.; ARAÚJO FILHO, J. C.; OLIVEIRA, J. B.; CUNHA, T. J. F. Sistema Brasileiro de Classificação de Solos. Brasília, DF: EMBRAPA Solos, 2018. 355 p.

SANTOS, L. S. Flutuação populacional, distribuição espacial e plano de amostragem sequencial de Anticarsia gemmatalis (Hübner, 1818) (Lepidoptera: Erebidae) e Chrysodeixis includens (Walker, 1858) (Lepidoptera: Noctuidae) em diferentes cultivares de soja. 2018. 62 p. Tese (Doutorado em Agronomia) - Faculdade de Ciências Agrárias e Veterinárias, Universidade Estadual Paulista, Jaboticabal, 2018. Disponível em: https://repositorio.unesp.br/bitstream/handle/11449/154238/santos_ls_dr_jabo.pdf?sequence= 3. Acesso em: 14 dez. 2020. 
STABACK, D.; BLANCL, P. L.; GALANTE, V. A.; Uso do MIP como estratégia de redução de custos na produção de soja no estado do Paraná. Revista Americana de Empreendedorismo e Inovação, Paranaguá, v. 2, n. 1, p.187-200, 2020. Disponível em: http://periodicos.unespar.edu.br/index.php/raei/article/view/3297. Acesso em: 14 dez.2020.

SAVIO, G. M.; PINOTTI, E. B.; Controle biológico da lagarta-da-soja (Anticarsia gemmatalis) por Baculovirus anticarsia. Revista Científica de Agronomia, Garça, v. 8 n. 13, p.1-7, 2008.2 Disponível em: http://faef.revista.inf.br/imagens_arquivos/arquivos_destaque/ABQIbvMGaRe80QG_2013-53-15-24-32.pdf. Acesso em: 14 dez. 2020.

SILVA, M. T. B. Controle da lagarta da soja (Anticarsia gemmatalis Hubner, 1818 Lepidoptera: Noctuidae). IV. Controle biológico Natural. Ciência Rural, Santa Maria, v. 23, n. 2, p.127-132, 1993. Disponível em: https://www.scielo.br/scielo.php?script=sci_arttext\&pid=S0103-84781993000200001. Acesso em: 14 dez. 2020.

SOSA-GÓMEZ, D. R.; MOSCARDI, F.; CORRÊA-FERREIRA, B. S.; OLIVEIRA, L. J.; HOFFMANN-CAMPO, C. B.; PANIZZI, A. R.; CORSO, I. C.; BUENO, A. F.; HIROSE, E.; GAZZONI, D. L.; OLIVEIRA, E. B.; Soja: manejo integrado de pragas. Curitiba: SENARPR / EMBRAPA-Soja, 2010. 83 p. Disponível: https://www.agencia.cnptia.embrapa.br/Repositorio/circtec30_000g46xpyyv02wx5ok0iuqaqk bbpq943.pdf. Acesso em: 14 dez. 2020.

STÜRMER, G. R.; FILHO, A. C.; SARI, B. G.; BURTET, L. M.; GUEDES, J. V. C.; Eficiência do pano-de-batida na amostragem de insetos-praga de soja em diferentes espaçamentos entre linhas e cultivares. Semina: Ciências Agrárias, Londrina, v. 35, n. 3, p.1177-1186, 2014. Disponível em: https://www.researchgate.net/publication/274655482_Eficiencia_do_pano-de batida_na_amostragem_de_insetospraga_de_soja_em_diferentes_espacamentos_entre_linhas _e_cultivares. Acesso em: 14 dez. 2020.

STURMER, G. R.; CARGNELUTTI FILHO, A.; STEFANELO, L. S.; GUEDES, J. V. C.. Eficiência de métodos de amostragem de lagartas e de percevejos na cultura de soja. Ciência Rural, Santa Maria, v. 42, n. 12, p.2105-2111, 2012. Disponível em: https://www.scielo.br/scielo.php?pid=S010384782012001200001\&script=sci_abstract\&tlng= pt. Acesso em: 14 dez.2020.

RIFFEL, C. T.; GARCIA, M. S.; SANTI, A. L.; BASSO, C. J.; DELlA FLORA, L. P.; CHERUBIN, M. R.; EITELWEIN, M. T.; Densidade amostral aplicada ao monitoramento georreferenciado de lagartas desfolhadoras na cultura da soja. Ciência Rural, Santa Maria, v. 42, n. 12, p.2112-2119, 2012. Disponível em: https://www.scielo.br/scielo.php?script=sci_arttext\&pid=S0103$84782012001200002 \& \operatorname{lng}=$ pt\&tlng=pt. Acesso em: 14 dez. 2020.

TONIN, R. F. B.; LUCCA FILHO, O. A.; LABBE, L. M. B.; ROSSETTO, M.; Potencial fisiológico de sementes de milho híbrido tratadas com inseticidas e armazenadas em duas condições de ambiente. Scientia Agropecuária, Trujillo, v. 5, n. 1 p.7-16, 2014. Disponível 
em: http://www.scielo.org.pe/scielo.php?script=sci_arttext\&pid=S207799172014000100001. Acesso em: 14 dez. 2020.

VIEIRA, E. C. S. Efeito de inseticidas aplicados nas sementes de soja sobre o controle de lagarta-elasmo e na mortalidade e consumo foliar de lagartas desfolhadoras da cultura. 2017. 55 f. Dissertação (Mestrado em Entomologia e Conservação da Biodiversidade) Universidade Federal da Grande Dourados, Dourados, 2017. Disponível em: http://repositorio.ufgd.edu.br/jspui/handle/prefix/1282. Acesso em: 14 dez. 2020.

WADE, M. R.; SCHOLZ, B. C. G.; LIOYD, A. J. C.; BERNIE, A. F.; ZALUCKI, M. P.; Temporal variation in arthropod sampling effectiveness: the case for using the beat sheet method in cotton. The Netherlands Entomological Society, Amsterdam, v. 120, n. 2, p.139153, 2006. Disponível em: https://europepmc.org/article/agr/ind43819692. Acesso em: 14 dez. 2020. 